\title{
The Volatility Spillover effect between the T-Note Spot and Futures Markets Evidence from China, Germany and United States
}

\author{
Zhao YANG \\ School of Business, East China University of Science and \\ Technology. \\ Institute of Financial Engineering, East China University \\ of Science and Technology \\ Shanghai, P. R. China. \\ E-mail: zyang9204@gmail.com
}

\author{
Fu-Tie SONG* \\ School of Business, East China University of Science and \\ Technology. \\ Institute of Financial Engineering, East China University \\ of Science and Technology \\ Shanghai, P. R. China. \\ E-mail: ftsong@ecust.edu.cn.
}

\begin{abstract}
This paper examines the volatility spillover effects in Treasury note markets, spot and futures markets, within and between three selected countries, China, Germany and United States. Two comprehensive explanatory methods, asymmetric BEKK MGARCH and asymmetric DCC MGARCH, are utilized to estimate interactions between markets and between countries. Compelling evidences show the presence of such volatility spillover effects between spot and futures markets for each targeted country. These spillover effects are also evident between the cross-border futures markets. However the existence of these effects are insignificant for spot markets between countries.
\end{abstract}

Keywords-treasury note; spillover effect; asymmetric DCC MGARCH; asymmetric BEKK MGARCH

\section{INTRODUCTION}

The first Treasury bond futures contract was written in USA in 1976. Since then, strong demands to hedge risks in spot markets have exponentially driven up such transactions. More than 24 countries or regions have been operating T-bond futures. Chicago Board of Trade (CBOT) in USA is the largest and most active one, and which is followed by European-orientated EUREX headquartered in Germany. Following an 18-year period closure, China re-listed its Treasury bond futures contract in China Financial Futures Exchange (CFFEX) in September 2013.

This paper intends to explore volatility spillover effects resulted from (a) interactions between T-note spot and futures markets for each country, and (b) interactions between countries for each market. As usual, we adopt the widely-accepted consent that sensitive new information available to market is the fundamental cause of any spillovers. Prior work has been concerned on (a) interactions respectively within, and (b) interactions between stock markets, exchange markets, oil markets and gold markets. However, there are few researches to investigate the objectives of this work. Specifically, the 3 exchange centers, CBOT, EUREX and CFFEX, are selected to analyze those interactions described above.

This paper contributes to the literature from at least the following three aspects. (a) Considering the difference of the trading time among different markets located in
North America, West Europe, and China (an emerging economy). (2) Supported by the Jarque-Bera test, the student's $t$ (rather than the normal) distribution fits better to the market logarithmic returns. (3) By combining asymmetric BEKK mutilate GARCH with asymmetric DCC mutilate GARCH, spillover effects have been examined on the directions, the effects by ARCH, GARCH and asymmetry effects respectively.

As a core result, volatility spillover effects exist in both spot and futures markets in the examined countries using asymmetric BEKK MGARCH and ADCC MGARCH tests. Specifically, spot market volatility exhibits a positive impact on the corresponding futures market whereas a negative impact has been observed on the retrospective relationship. As a further key result, futures markets exhibit spillover effects across countries and spot markets do not.

The remaining paper is organized as follows. Section 2 reviews literatures. Section 3 elaborates data sources, data processing methods and descriptive statistic checks. Section 4 introduces the models used. Section 5 documents the spillover effects. Section 6 concludes the paper.

\section{LITERATURE REVIEW}

Increasing evidence shows correlations both between markets and between assets. One such correlation is between volatilities (expressed by variance) over the time series. Volatility spillover effect means that the present volatility of a market is not only affected by its past volatility, but also the volatility in the other market(s).

Five established modeling approaches can be used to analyze spillover effects, and these are (a) vector autoregressive model (VAR), (b) co-integration analysis, (c) generalized autoregressive conditional heteroscedasticity $(\mathrm{GARCH})$ model, (d) SV model, and (e) the approach by Diebold $(2009 ; 2012)$. GARCH and its variants have been more preferred by convention.

Based on the ARCH model by Engle (1982), Bollerslev (1986) developed the GARCH model by embracing conditional heteroskedasticity. Compared to ARCH model, GARCH model more accurately quantifies 
the residual heteroskedasticity of asset returns over time series. Further modeling endeavors to GARCH have been under way. Engle (1995) simplified the VEC model to the Baba-Engle-Kraft-Kroner (BEKK) GARCH model. To avoid the trouble of constructing variance-covariance matrix, Bollerslev (1990) changed to model correlation matrix, and thus developed the Constant Conditional Correlation (CCC) GARCH model. Tse (2000) and Engle (2002) improved the CCC GARCH to Dynamic Conditional Correlation (DCC) GARCH model to allow correlations over changing times. Based on the Engle's work, Palandri (2007) developed the Sequential Conditional Correlations (SCC) GARCH model and have successfully solved the calculation problems caused by high-dimension modeling. Further modeling attempts have also been documented in the literature. For instance, Zhang (2009) has made a factor analysis and developed a factor DCC model.

GARCH model and its derivatives have been wildly used in testing volatility spillover effects. Koutmos (1995) used multivariate EGARCH structure to quantify spillover effects for the US, London and Tokyo stock markets. Karolyi (1995) employed the 2D BEKK-GARCH model to investigate the volatility spillover effect over the stock markets in the US and Canada. Jeong (1999) tested the Spillover effect on stock markets in the US, UK and Canada covering different trading time zones with the DCC-GARCH model. Tes (1999) measured the bi-directional information flow based on bivariate EGARCH model. Using the EGARCH model, Kanas (2000) analyzed links between stock market and the exchange market for the main western countries. Bodart $(2001)$ used bivariate $\operatorname{GARCH}(1,1)$ model and weekly data to explore the links between volatility of exchange rate market and stock market' return for 7 industrial countries in Europe. Wu (2005) explored intraday spillover effects between S\&P500 and FTSE 100 using the GARCH model, and identified bi-direction spillover effects for these markets. Chiang (2007) applies the DCC-GARCH model to explore the spillover effect in 9 Asian markets, and indicated the significance of international sovereign credit-rating agencies. Kim (2011) used DCCX-GARCH model to explore the spillover effects of the recent US financial crisis on the emerging Asian markets. Walid (2011) proposed a novel MS-GARCH model to ascertain relationships between exchange market and stock market for 4 emerging countries/regions, Hong Kong, Singapore, Malaysia and Mexico. Tao (2012) explored correlations between FTSE100 spot and futures market using ADCC-TGARCH-M analysis. Kim (2013) applies DCCX-GARCH to discover spillover effects between Japanese Yen and emerging Asian currencies. Chakrabarty (2015) relied on the Wavelet-based MRA-EDCC-GARCH to find connections between News and Volatility Spillover over the Indian Financial Market.

\section{DATA AND RESEARCH METHOD}

In this section, we present the data selection and the corresponding pretreatment procedures. A descriptive statistic of the data is listed below.

\section{A. Data and Sample Selection}

In order to make a matching time period comparison for the 3 exchange centers, a 5-year maturity T-note futures contract is selected. Wind Financial terminal is utilized for collecting daily close price in the Chinese T-note spot and futures markets, and Bloomberg Financial terminal for the Germen and the US counterparts.

For futures contracts, the rolling-window methodology is used to convert individual contracts over different time periods into a continuous time varying series. For each quarterly expiry contract, trading activities are inactive with almost no liquidity and little trading until the last 5-6 months. Consequently, only the last 3-month data prior to the delivery month of each contract are collected. The whole period for cross-market and cross-country analyses is from 01 November 2013 to 31 August 2015. This period excludes possible abnormal data over a learning period of the Chinese market following re-listing.

For spot contracts, T-Note indexes are utilized. Five-year Treasury note index based on cleaning price is used for the Chinese spot data, and 3-5-year Treasury note index, provided via Bloomberg, is utilized for the German and US data.

\section{B. Data Pretreatment and Descriptive Statistics}

Financial assets are usually non-stationary. To make them stationary, logarithmic returns are therefore made on the original data. For convenience, each return is amplified by a factor of 100 , and this is shown as eq. (1).

$$
\begin{aligned}
P_{t} & =100 \times\left(\ln \text { Price }_{t} \ln \text { Price }_{t-1}\right) \\
& =100 \times \ln \frac{\text { Price }_{t}}{\text { Price }_{t-1}}
\end{aligned}
$$

Where Price is the close price of assets, and $\mathrm{P}$ is the logarithmic return.

Consistent with kurtosis and skewness anomaly, non-normal distribution outcome is confirmed by Jarque-Bera test. Consequently, the time varying series should not be treated to abide by Gaussian distribution. Unfortunately, much literature does not pay attention to this. Student's distribution is used and confirmed to all the models.

\section{METHODOLOGIES}

Two multivariate GARCH models are employed to measure the volatility spillover effects. These models have 2 main advantages. First, possible relationships between different return series can be identified while the $\mathrm{ARCH}$ effects are measured, and meanwhile avoiding the inconvenience of regressing respectively. Second, multivariate GARCH models can be used to explain certain volatility spillover effects caused by the same news over different markets. 
Asymmetric BEKK GARCH was improved via Kroner and Ng (1998). In the asymmetric item on the right-hand side lies the key difference between asymmetric BEKK GARCH and standard BEKK GARCH. The dummy variable, $\eta$, is added to account for this effect with value being zero or $-\varepsilon_{\mathrm{it}}$ whichever is larger. The error term is described by $\varepsilon_{\text {it }}$. These equations are shown below.

$$
\begin{aligned}
& P_{t}=\left(\begin{array}{l}
P_{1, \mathrm{t}} \\
P_{2, \mathrm{t}}
\end{array}\right)=\left(\begin{array}{l}
\text { Constant }_{1} \\
\text { Constant }_{2}
\end{array}\right)+\left(\begin{array}{ll}
\alpha_{11} & \alpha_{12} \\
\alpha_{21} & \alpha_{22}
\end{array}\right)\left(\begin{array}{l}
P_{1, \mathrm{t}-1} \\
P_{2, \mathrm{t}-1}
\end{array}\right)+ \\
& \left(\begin{array}{l}
\mu_{1, \mathrm{t}} \\
\mu_{2, \mathrm{t}}
\end{array}\right) \text {, where } \mu_{t} \mid \Omega_{t-1} \sim t\left(0, H_{t}\right) \text {. } \\
& \mathrm{H}_{t} \mathrm{D}_{\mathrm{t}} \mathrm{R}_{\mathrm{t}} \mathrm{D}_{\mathrm{t}} \text {. } \\
& \mathrm{D}_{\mathrm{t}}=\left(\begin{array}{cc}
\sqrt{\mathrm{h}_{1, \mathrm{t}}} & 0 \\
0 & \sqrt{\mathrm{h}_{2, \mathrm{t}}}
\end{array}\right) \\
& R_{t}=\left(\begin{array}{cc}
1 & \rho_{12, t} \\
\rho_{12, t} & 1
\end{array}\right)
\end{aligned}
$$$$
H_{t}=W W^{\prime}+A^{\prime} \varepsilon_{t-1} \varepsilon_{t-1}^{\prime} A+B^{\prime} H_{t-1} B+
$$$$
C^{\prime} \eta_{t-1} \eta_{t-1}^{\prime} C \text {. }
$$

Where $\mu_{\mathrm{t}}$ is the residual vector of the return, $\Omega_{\mathrm{t}-1}$ denotes available information set at time $\mathrm{t}-1, \eta_{\mathrm{t}}$ is the dummy variable and $\mathrm{H}_{\mathrm{t}}$ is the conditional covariance matrix. Spillover directions between the markets are detected based on parameters $B_{12}$ and $\mathrm{B}_{21}$.

Asymmetric DCC GARCH (eqs. 7 to 14) is an analogy to the above multivariate model.

$$
\begin{gathered}
Q_{t}= \\
\left(\bar{Q}-A^{\prime} \bar{Q} A-B^{\prime} \bar{Q} B-C^{\prime} \bar{N} C\right)+A^{\prime} \mu_{t-1} \mu_{t-1}^{\prime} A+ \\
B^{\prime} Q_{t-1} B+ \\
C^{\prime} \eta_{t-1} \eta_{t-1}^{\prime} \mathrm{C}
\end{gathered}
$$

$$
\begin{gathered}
\bar{Q}=T^{-1} \sum_{t}^{T} \mu_{t} \mu_{t}^{\prime} \\
\bar{N}=T^{-1} \sum_{t}^{T} \eta_{t} \eta_{t}^{\prime} \\
\eta_{i, t}=\overrightarrow{1}_{\left[\mu_{i, t}<0\right]} \mu_{i, t} \\
\mu_{i, t}=\frac{\varepsilon_{i, t}}{\sqrt{h_{i, t}}}, i=1,2 \\
R_{t}=Q_{t}^{*-1} Q_{t} Q_{t}^{*-1}
\end{gathered}
$$

\begin{tabular}{|c|c|c|c|c|c|c|}
\hline & $\mathrm{B}(1,2)$ & $\mathrm{B}(2,1)$ & $\mathrm{ADCC} 1$ & $\mathrm{ADCC} 2$ & $\mathrm{ADCC} 3$ & Shape \\
\hline \multirow{2}{*}{$\mathrm{CN}$} & $-0.1766^{* *}$ & $0.5878^{* *}$ & $0.1315^{* *}$ & $0.1625^{* *}$ & $0.1625^{* * *}$ & $4.7632^{* * *}$ \\
\cline { 2 - 7 } & $(4.663)$ & $(2.356)$ & $(57.18)$ & $(126.27)$ & $(143.03)$ & $(710.88)$ \\
\hline \multirow{2}{*}{$\mathrm{DE}$} & $-1.061^{* *}$ & $2.103^{* *}$ & $0.3650^{* *}$ & $0.6350^{* *}$ & $-0.9922^{* * *}$ & $2.2852^{* *}$ \\
\cline { 2 - 7 } & $(2.723)$ & $(3.160)$ & $(307.8)$ & $(3.73)$ & $(2.624)$ & $(32.033)$ \\
\hline \multirow{2}{*}{ US } & -0.1746 & $1.3472 * *$ & $0.4386^{* *}$ & $0.561 * *$ & -0.5763 & $2.6391 * *$ \\
\cline { 2 - 7 } & $(0.3525)$ & $(2.275)$ & $(6.914)$ & $(9.211)$ & $(1.437)$ & $(53.613)$ \\
\hline
\end{tabular}

$$
\begin{aligned}
Q_{t}^{*} & =\operatorname{diag}\left(\sqrt{q_{i, i, t}}\right) \\
\mathrm{h}_{\mathrm{i}, \mathrm{t}}^{2} & =\mathrm{C}_{\mathrm{i}}+\mathrm{A}_{\mathrm{i}} \varepsilon_{\mathrm{i}, \mathrm{t}-1}^{2}+\mathrm{B}_{\mathrm{i}} \mathrm{h}_{\mathrm{i}, \mathrm{t}-1}^{2}+\mathrm{D}_{\mathrm{i}} \overrightarrow{1} \eta_{\mathrm{i}, \mathrm{t}-1}^{2}
\end{aligned}
$$

ADCC1, ADCC2 and ADCC3 resulted from ADCC GARCH model are the three key indicators. Respectively, $\mathrm{ADCC} 1, \mathrm{ADCC} 2$ and $\mathrm{ADCC} 3$ reflect connection between two markets, long term effect and volatility clustering, and asymmetric effect.

The two models above are used to analyze time series and to final results via the BFGS algorithm (a quasi-Newton algorithm). Software RATs 9.0 is used here.

\section{RESULTS AND ANALYSIS}

This section presents findings in both cross-market and cross-country dimensionalities. The t-distribution assumption is proven to be valid and this is consistent with most of social-economy systems.

\section{A. Spillover Effect Over Markets}

In this part, the cross-market spillover effect is tested for each of the 3 countries. In Table I shows key parameters concerned, with t-statistics and t-test significance.

\section{TABLE I SPILLOVER EFFECTS OVER T-NOTE} FUTURES AND SPOT MARKETS FOR EACH COUNTRY.

Note: Respectively 451, 467 and 461 samples were used for China (CN), Germany (DE) and the United States (US). For each country-based panel, the first row shows returned values with significance level labelling and the second row the corresponding t-values. B $(1,2)$ refers to the spillover effect directed from futures market to spot market, and B $(2,1)$ the same in the opposite direction. ADCC1 to ADCC3 reflect ARCH effect, GARCH effect and the asymmetric effect respectively. The last column tests the validity of the student's $t$ distribution hypothesis. Symbols *,** stand for $10 \%$ and $5 \%$ significant levels respectively. 
Take a panoramic view, spillover effects are identified between a T-note spot and futures markets for each country. Such spillover effect is bidirectional for China and Germany. This means that the volatility of futures market decreases the corresponding volatility in its spot market, and the volatility of spot market boosts the corresponding volatility in its futures market. However, as for United States, only the directional effect from the spot market to the futures market is statistically significant. For all the countries selected, it is always true that spot market volatility is positively related to that in futures market. For China and Germany (not for the US), presence of futures market restrains the volatility in its spot market. These properties confirm the necessities of setting up futures market by government in the first place.

With regard to the ADCC1 values for the ARCH effect, the US records the highest level whereas China the weakest. Given that a high ADCC1 value underlines maturity of a country's financial markets, results presented in this paper are thus consistent with widely confirmed opinion that CBOT is the best and EUREX is an active futures markets. On the contrary, futures market in China still needs time and effects for advance to a higher levels. Presently in China, large investors like commercial banks and insurance institutions are prohibited from entering into this market whereas market access filters out a vast number of medium and small investors. The all-positive ADCC2 values indicates that each observed spillover effect is long-term. China and Germany, not the US, exhibit the asymmetric effect by the ADCC3 parameter. Interestingly, direction of this effect for West Europe and China is different. Spillover effect decrease upon negative news in West Europe whereas enhances in China between spot and futures markets.

\section{B. Spillover Effect Over Countries}

In exploring cross-country spillover effects, full account of trading time is necessary, and this is compared in Figure 1.

Figure 1. Trading hour comparison in different exchange centers using Beijing Time.

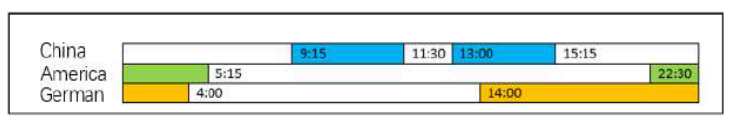

For non-overlapping trading hours in China and Germany, an analysis can be separated into two parts. The first part is based upon returns in the same date and therefore the volatility in China takes place earlier than Germany. The second part is based upon the German returns one date ahead of the Chinese data. However, 75-min difference in trading closure times between Germany and the US has been ignored, so time series in the 2 countries are regarded synchronously. Consequently, 5 analyses are required in exploring these cross-country spillover effects.

In view of differed holiday arrangements, a further adjustment is made to embrace simultaneous business days for all the 3 countries. As such, our analysis was made on 433 working days in total.

Respectively data were rearranged for all futures markets and spot markets over countries. No significant over-country ADCC results were detected for index analysis. And thus cross-country spillover effects for index or spot part are excluded.

Table II summarizes the results for the futures returns series over countries. The first panel of Table II shows the leading effect of China compared with the German futures market while panel 2 shows the effect compared with the US futures market. Panel 3 exhibits the spillover effect between the futures markets in Germany and the US. Panel 4 and panel 5 swap the leading part from China to Germany and US respectively for futures markets.

TABLE II CROSS-COUNTRY SPILLOVER EFFECTS IN FUTURES MARKETS.

\begin{tabular}{|c|c|c|c|c|c|c|}
\hline & $\mathrm{B}(1,2)$ & $\mathrm{B}(2,1)$ & $\mathrm{ADCC} 1$ & $\mathrm{ADCC} 2$ & $\mathrm{ADCC} 3$ & Shape \\
\hline \multirow{3}{*}{$\mathrm{CN}-\mathrm{DE}$} & 0.0339 & $\begin{array}{c}-0.0381^{*} \\
*\end{array}$ & $0.1811^{* *}$ & $0.1826^{* *}$ & $0.1827^{* *}$ & $4.861^{* *}$ \\
\cline { 2 - 7 } & $(1.366)$ & $(28.92)$ & $(296.2)$ & $(315.9)$ & $(316.8)$ & $(1228)$ \\
\hline \multirow{3}{*}{ CN-US } & $0.2341^{* *}$ & $\begin{array}{c}-0.3883^{*} \\
*\end{array}$ & $1.0 \mathrm{E}-6$ & $0.1392^{* *}$ & $-0.2524 * *$ & $4.8604 * *$ \\
\cline { 2 - 7 } & $(14.01)$ & $(16.01)$ & $(0.914)$ & $(97.04)$ & $(9.598)$ & $(320.9)$ \\
\hline \multirow{3}{*}{ DE\&US } & $-0.6454^{* *}$ & $0.3839 * *$ & $0.1609 * *$ & $\begin{array}{c}0.16942^{*} \\
*\end{array}$ & $0.1700^{* *}$ & $4.5804^{* *}$ \\
\cline { 2 - 7 } & $(3.416)$ & $(6.081)$ & $(99.01)$ & $(167.1)$ & $(178.0)$ & $(243.4)$ \\
\hline \multirow{2}{*}{ DE-CN } & 0.3031 & 0.0131 & 0.0098 & 0.4370 & -0.1602 & $4.3809 * *$ \\
\cline { 2 - 7 } & $(1.338)$ & $(0.241)$ & $(0.000)$ & $(0.143)$ & $(0.001)$ & $(2.935)$ \\
\hline \multirow{2}{*}{ US-CN } & $-0.044663 *$ & 0.042620 & 0.154906 & 0.155538 \\
& $* .510$ & 4.552 & 122.340 & 126.974 & 128.870 & 714.323 \\
\cline { 2 - 7 }
\end{tabular}

Note: The analysis concerns with 432 samples. For each country-based panel, the first row gives rise to returned values with significance level labelling, and the second row the corresponding t-values. B $(1,2)$ refers to the spillover effect between futures markets directed from leading to lagging country, and B $(2,1)$ the same in the opposite direction. ADCC1 to ADCC 3 reflect the ARCH effect, GARCH effect and the asymmetric effect respectively. The last column tests the validity of the student's $t$ distribution hypothesis. Symbols *, ** stand for $10 \%$ and $5 \%$ significant levels respectively.

With China being leading country, it is observed that volatility in Germany or the US significantly restrains that in China. Nevertheless, volatility in Chinese futures market only significantly amplifies that in the US but not that in Germany. Negative news improves futures markets connection between Germany and China whereas it weakens that between the US and China. Therefore, futures markets for Germany and China tend to be synchronized whereas those for US and China asynchronous. Long-term (i.e. GARCH) effects are identified both between Germany and China, and between US and China. Short-term (i.e. ARCH) effects are identified only between China and Germany.

With China being the lagging country, is only detected such volatility connection between US and China, and not between Germany and China. Between US and China, (i) $\mathrm{ARCH}$ effect turns out to be significant, (ii) negative news improves connections between the markets, (iii) 
volatility orientation, its effect and GARCH effects are identical or similar between them.

Between Germany and the US futures markets, spillover effects are significantly bi-directional. In view of close connections of the Western economies, this broadly fits to common sense expectations.

\section{CONCLUSION}

This paper has explored volatility spillover effects in different markets and countries. Countries selected represent emerging economy, Western Europe and North America respectively. Volatility asymmetries have been studied using asymmetric BEKK MGARCH and ADCC MGARCH models. Time varying series is confirmed to follow $\mathrm{t}$ distribution instead of normal distribution. Volatility direction and properties (primarily long-term and short-term effects) of volatility spillover effects have been satisfactorily identified.

The spillover effects can be categorized as cross-market and cross-country. For the cross-market dimension, spillover effects widely exist between T-note spot and future markets for each country, and are strengthened by market activity improvement. Asymmetric effects are confirmed by the ADCC 3 values using ADCC MGARCH model. Negative news has been indicated to affect each market differently: enhance connection in China, weaken connection in Germany, and no significant impact in the US. For the cross-country dimension, few effects have been detected for T-note spot markets. For futures markets in this dimension, leading or lagging country methodology is applied separately to reflect difference in trading hours, and outcomes obtained are indeed different. With China being the leading country, volatility in Germany or US leads to a suppressed level of the same in China. On the other hand, volatility in China only boosts the US futures market. With China being the lagging country, no significant relationship between Germany and China is substantiated, and a 2-way significant relationship are discovered between the US and China. A similar 2-way significant relationship between Germany and the US are confirmed to be the same as our prior knowledge.

\section{ACKNOWLEDGMENT}

This research was partially supported by the National Natural Science Foundation of China (Fund Number: 71371073) and Shanghai Pujiang Program of China (Fund Number: 13PJC025).

\section{REFERENCE}

[1] Bodart, V., Reding, P. 2001. Do foreign exchange markets matter for industry stock returns? An empirical investigation. Discussion paper, 2001.

[2] Bollerslev, T. 1986. Generalised autoregressive conditional heteroscedasticity. Journal of Econometrics, 31, 307-327.
[3] Bollerslev, T. 1990. Modelling the coherence in short-run nominal exchange rates: a multivariate generalized $\mathrm{ARCH}$ model. The Review of Economics and Statistics, 498-505.

[4] Chakrabarty, A., De, A., Bandyopadhyay, G. 2015. A Wavelet-based MRA-EDCC-GARCH Methodology for the Detection of News and Volatility Spillover across Sectoral Indices-Evidence from the Indian Financial Market. Global Business Review, 16(1), 35-49.

[5] Chiang, T. C., Jeon, B. N., Li, H. 2007. Dynamic correlation analysis of financial contagion: Evidence from Asian markets. Journal of International Money and Finance, 26(7), 1206-1228.

[6] Diebold, F. X., Yilmaz, K. 2009. Measuring financial asset return and volatility spillovers, with application to global equity markets*. The Economic Journal, 119(534), 158-171.

[7] Diebold, F. X., Yilmaz, K. 2012. Better to give than to receive: Predictive directional measurement of volatility spillovers. International Journal of Forecasting, 28(1), 57-66.

[8] Engle, R. F. 2002. Dynamic conditional correlation: A simple class of multivariate generalized autoregressive conditional heteroskedasticity models. Journal of Business \& Economic Statistics, 20(3), 339-350.

[9] Engle, R. F. 1982. Autoregressive conditional heteroscedasticity with estimates of the variance of United Kingdom inflation. Econometrica: Journal of the Econometric Society, 987-1007.

[10] Engle, R. F., Kroner, K. F. 1995. Multivariate simultaneous generalized ARCH. Econometric Theory, 11, 122-150.

[11] Jeong, J. G. 1999. Cross-border transmission of stock price volatility: evidence from the overlapping trading hours. Global Finance Journal, 10(1), 53-70.

[12] Kanas, A. 2000. Volatility spillovers between stock returns and exchange rate changes: international evidence. Journal of Business Finance \& Accounting, 27(3-4), 447-467.

[13] Kim, B., Kim, H. 2011. Spillover effects of the U.S. financial crisis on financial markets in emerging Asian countries. International Review of Economics \& Finance, 39, 192-210.

[14] Kim, B., Kim, H., Min, H. 2013. Reassessing the link between the Japanese yen and emerging Asian currencies. Journal of International Money and Finance, 33, 306-326.

[15] Karolyi, G. A. 1995. A multivariate GARCH model of international transmissions of stock returns and volatility: The case of the United States and Canada. Journal of Business and Economic Statistics, 13(1), 11-25.

[16] Koutmos, G., Booth, G. G. 1995. Asymmetric volatility transmission in international stock markets. Journal of international Money and Finance, 14(6), 747-762.

[17] Palandri, A. 2007. Sequential conditional correlations: Inference and evaluation. Journal of Econometrics, 153(2), 122-132.

[18] Tao, J., Green, C. J. 2012. Asymmetries, causality and correlation between FTSE100 spot and futures: A DCC-TGARCH-M analysis. International Review of Financial Analysis, 24(C), 26-37.

[19] Tse, Y. K. Tsui, A. K. 2000. A multivariate GARCH model with time-varying correlations. Journal of Applied Econometrics, 7, 259-279.

[20] Walid, C., Chaker, A., Masood, O., \& Fry, J. 2011. Stock market volatility and exchange rates in emerging countries:A Markov-state switching approach. Emerging Markets Review, 12(3), 272-292.

[21] Wu, C., Li, J., Zhang, W. 2005. Intra daily periodicity and volatility spillovers between international stock index futures markets. Journal of Futures Markets, 25(6), 553-585.

[22] Zhang, K., Chan, L. 2009. Efficient factor GARCH models and factor-DCC models. Quantitative Finance, 9(1), 71-91. 